\title{
Studi Awal Perancangan Tempat Tidur Pasien Berbahan Aluminium dengan Metode Elemen Hingga
}

\author{
Suyitno, ${ }^{1, *}$ F.A.K. Yudha ${ }^{1}$ \\ 1Departemen Teknik Mesin dan Industri, Fakultas Teknik,Universitas Gadjah Mada \\ Jl. Grafika No.2, Yogyakarta 55281 \\ Telp. +62-274-521673 \\ e-mail: *1suyitno@ugm.ac.id
}

\begin{abstract}
Abstrak
Tempat tidur rumah sakit adalah tempat tidur yang dirancang untuk orang yang membutuhkan perawatan kesehatan. Tempat tidur ini memiliki fitur untuk kenyamanan pasien, mencakup ketinggian kepala, kaki, rel samping yang dapat disesuaikan manual atau otomatis, pembuatan tempat tidur pasien saat ini masih menggunakan bahan baja dan stainless steel. Stainless steel dikenal banyak digunakan sebagai alat biomedik, contoh implan, pisau operasi, dan alat bantu rumah sakit seperti tempat tidur pasien karena tahan korosi, dari keluhan perawat rumah sakit untuk tempat tidur pasien saat ini yang berbahan stainless steel masih berat disaat memindahkan tempat tidur dari ruang satu ke ruang yang lain. Untuk itu di buat studi awal perancangan tempat tidur pasien berbahan alumunium yang akan menggantikan bahan stainless steel dimana nantinya akan mendapatkan tempat tidur yang ringan dan mampu menahan beban $250 \mathrm{~kg}$. Studi awal perancangan menggunakan bantuan CAD untuk membuat desain dan Software Abaqus 6.11 dalam menganalisis tempat tidur pasien. Studi awal ini membuat tempat tidur pasien yang diperkecil dengan skala 1:5. Hasil simulasi tempat tidur pasien skala 1:5 dengan beban $600 \mathrm{~N}$ menghasilkan Von Mises sebesar $67 \mathrm{MPa}$ dan displacement sebesar 1,7 mm. Untuk itu hasil tegangan (Von Mises) simulasi tempat tidur pasien nilainya lebih kecil dari yield strength aluminium 6061 T6 sebesar $275 \mathrm{Mpa}$ maka bahan yang digunakan untuk tempat tidur pasien masih aman. Hasil eksperimen tempat tidur pasien skala 1:5 dengan beban $600 \mathrm{~N}$ menghasilkan displacement sebesar 1,68 mm.
\end{abstract}

Kata kunci: Abaqus 6.11, Tempat Tidur Pasien, CAD, Aluminium.

\begin{abstract}
Hospital beds are beds that are designed for people who need health care. This bed has features for patient comfort, including head, foot height, side rails that can be adjusted manually or automatically, while making patient beds is still using steel and stainless steel. Stainless steel is known to be widely used as a biomedical tool, for example implants, surgical knives, and hospital aids such as patient beds because of corrosion resistance, from complaints of hospital nurses to patient beds today that are still heavy stainless steel when moving beds from room one to another room. For this reason, a preliminary study of the design of a patient bed made of aluminium will be replaced by stainless steel, which will later get a lightweight bed that can withstand a load of $250 \mathrm{~kg}$. The preliminary design study used CAD assistance to design and Software Abaqus 6.11 in analyzing patient beds. This initial study made the patient's bed minimized on a 1: 5 scale. The results of the simulation of the patient bed scale 1: 5 with a load of $600 \mathrm{~N}$ resulted in Von Mises of $67 \mathrm{MPa}$ and displacement of $1.7 \mathrm{~mm}$. For the results of the stress simulation (Von Mises) of the patient's bed the value is smaller than the yield strength of aluminium 6061 T6 of 275 Mpa, the material used for the patient's bed is
\end{abstract}


still safe. The experimental results of patient beds on a 1:5 scale with a load of $600 \mathrm{~N}$ resulted in a displacement of $1.68 \mathrm{~mm}$.

Keywords: Abaqus 6.11, Patient Beds, CAD, Aluminium

\section{PENDAHULUAN}

Pelayanan rumah sakit untuk pasien sangat diprioritaskan. Tingkat kenyamanan pasien mencerminkan kuwalitas rumah sakit yang profesional. Peralatan canggih dalam dunia medika sangat diperlukan untuk proses penyembuhan pasien. Tempat tidur rumah sakit adalah tempat tidur yang dirancang khusus untuk pasien rawat inap atau orang lain yang membutuhkan beberapa bentuk perawatan kesehatan. Tempat tidur ini memiliki fitur khusus baik untuk kenyamanan pasien dan untuk kenyamanan petugas layanan kesehatan. Fitur umum mencakup ketinggian yang dapat disesuaikan untuk seluruh tempat tidur, kepala, dan kaki, rel samping yang dapat disesuaikan, dan tombol elektronik untuk mengoperasikan tempat tidur. Tempat tidur rumah sakit digunakan tidak hanya di rumah sakit, namun juga di fasilitas perawatan kesehatan lainnya, seperti panti jompo, klinik rawat jalan, dan perawatan kesehatan yang ada di rumah.

Tempat tidur pasien di rumah sakit sekarang ini masih menggunakan bahan baja dan stainless steel dari data spesifikasi tempat tidur pasien dimana berat total berkisar dari $100 \mathrm{~kg}$ sampai $200 \mathrm{~kg}$, sehingga dari keluhan perawat rumah sakit untuk tempat tidur pasien saat ini yang berbahan stainless steel masih berat disaat memindahkan tempat tidur dari ruang satu ke ruang yang lain.

Tempat tidur pasien dikembangkan menggunakan teknologi dimana tempat tidur tersebut tidak hanya dapat digerakkan secara manual tetapi dapat digerakkan secara otomatis, yang mengakibatkan harga tempat tidur tersebut menjadi mahal, data standar tempat tidur pasien dengan panjang $2 \mathrm{~m}$, lebar $90 \mathrm{~cm}$, tinggi $60 \mathrm{~cm}$, dan berat total mencapai $200 \mathrm{~kg}$

Dari standar tempat tidur tersebut untuk itu di buat studi awal perancangan tempat tidur pasien berbahan alumunium yang akan menggantikan bahan baja dan stainless steel dimana nantinya akan mendapatkan tempat tidur yang ringan dan mampu menahan beban $250 \mathrm{~kg}$ atau sesuai dengan berat badan orang dewasa yang mengalami obesitas. Dengan penggantian bahan tempat tidur pasien dengan bahan alumunium yang dijual di pasaran diharapkan bisa menjangkau harga tempat tidur pasien yang tadinya mahal bisa menjadi murah dengan teknologi yang sama, terdapat pada tempat tidur pasien tersebut. Dengan menggunakan bantuan software $C A D$ untuk membuat desain tempat tidur pasien dengan skala 1:5 dan software Abaqus 6.11 dalam menganalisis desain tempat tidur pasien berbahan alumunium skala 1:5 yang mampu untuk menahan berat merata maksimal $600 \mathrm{~N}$ yang nantinya studi awal perancangan ini dipakai untuk awal pembauatan tempat tidur pasien yang aman. (Fisher, 2011).

\section{METODE PENELITIAN}

Penelitian ini terdiri perancangan, pembuatan, dan eksperimen prototipe tempat tidur pasien dengan skala 1:5. Langkah-langkah penelitian disusun dalam diagram alir yang ditampilkan pada Gambar 1. 


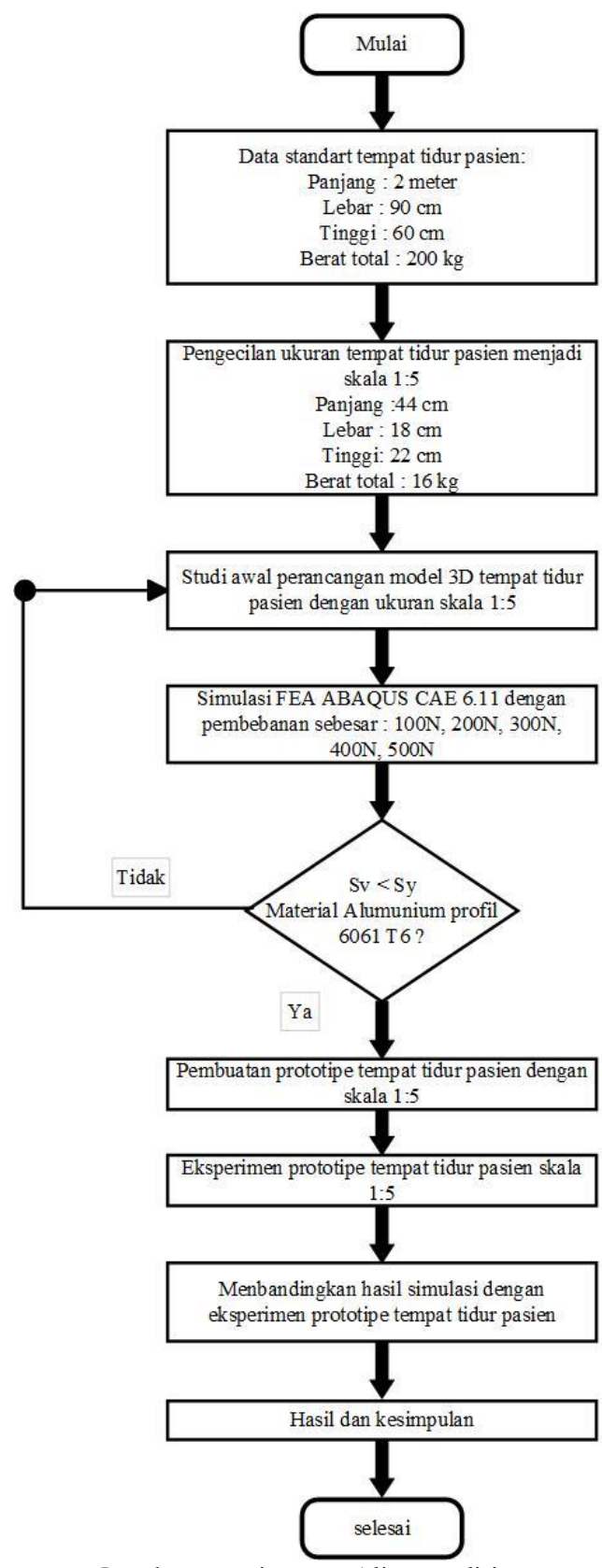

Gambar 1. Diagram Alir penelitian

Pengujian prototipe untuk perbandingan dengan skala 1:5 pengujian statis dengan pembebanan terdistribusi merata dan alat ukur yang digunakan adalah dial indikator. Untuk pengambilan data sesuai dengan beban yang dinginkan, setiap pengambilan data satu beban sebanyak sepuluh kali dan dicatat setelah itu diambil nilai rata-rata. Untuk proses pengujian ditampilkan pada gambar 2 . 


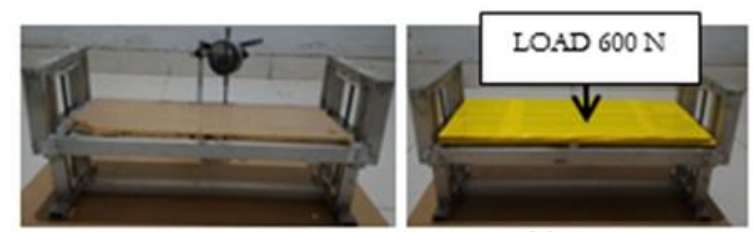

Gambar 2. Proses pengujian tempat Tidur skala 1:5

Dengan pengambilan data displacement prototipe ini yang nantinya akan dibandingkan dengan data yang diperoleh dari simulasi diambil batasan displacement untuk pengujian ini adalah $10 \mathrm{~mm}$, dimana displacement $10 \mathrm{~mm}$ itu diambil sebagai batas maksimum aman dikarenakan tempat tidur pasien yang dirancang ini membutuhkan tingkat ke presisian yang tinggi, mengingat peracangan penggerak tempat tidur pasien ini menggunakan sistem elektrik dan penggerak rangka menggunakan linier actuator.

\section{HASIL DAN PEMBAHASAN}

Perancangan model diperoleh dari informasi dimensi ukuran tempat tidur pasien. Pembuatan bentuk dan ukuran mencermati pada tempat tidur pasien yang sudah diproduksi dan beredar yaitu produk Invancare dengan data standar tempat tidur pasien dengan panjang 2 $\mathrm{m}$, lebar $90 \mathrm{~cm}$, tinggi $60 \mathrm{~cm}$, dan berat total mencapai $200 \mathrm{~kg}$. Model awal rancangan harus memenuhi kriteria fungsi dari tempat tidur pasien dan menggunakan Aluminium 6061 T6 sebagai bahan yang digunakan untuk membuat tempat tidur pasien. Model tempat tidur pasien digambar dalam 3D menggunakan software Solid Work 2016. Tahap merancang harus mempertimbangkan proses manufatur yang hanya menggunakan metode permesinan konvensional. File desain tersebut diekspor kedalam format parasolid (.x_t) sehingga dapat dilakukan proses simulasi menggunakan software ABAQUS 6.11.

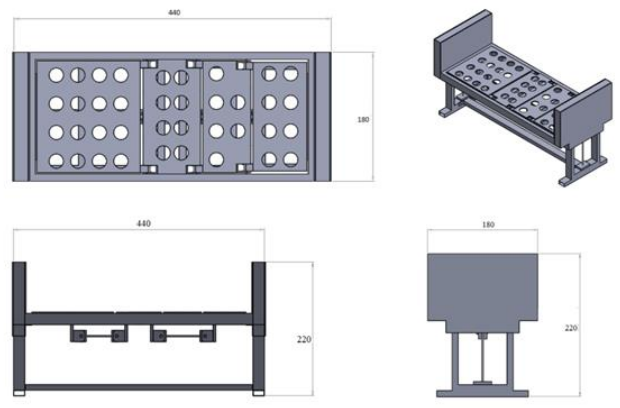

Gambar 3. Desain 3D model Prototipe

\section{Simulasi FEA}

Proses ini akan berpengaruh besar dalam mengurangi biaya operasional suatu pekerjaan. Selain itu, simulasi bisa menjadi salah satu cara untuk mempertimbangkan kelayakan dari suatu desain. Penggunaan perangkat lunak simulasi dalam penelitian ini bertujuan untuk menganalisis distribusi tegangan dan displacement yang terjadi pada model desain tempat tidur pasien berbahan aluminium. Hasil dalam simulasi yang diperoleh dari software Abaqus 6.11 menjadi dasar bahwa desain tersebut aman dari kegagalan mekanik. Uji simulasi dilakukan dengan model static general. Pembebanan aksial maksimal sebesar $600 \mathrm{~N}$ 
dan pembebanan minimal $100 \mathrm{~N}$. Hasil tegangan (Von Mises) dan displacement dijadikan sebagai indikator kegagalan mekanik dari model tempat tidur pasien tersebut. Model simulasi ditunjukkan Gambar 4 dan diberikan gaya pembebanan.

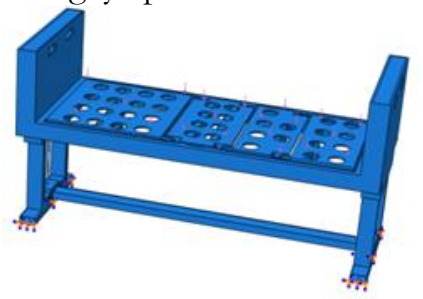

Gambar 4. Simulasi beban yang didapat tempat tidur skala 1:5

\section{Hasil pembebanan tekan}

Model ini posisi tempat tidur pasien mendatar dan memperoleh beban aksial. Hasil simulasi ditunjukkan Tabel 1.

Tabel 1. Hasil simulasi model prototipe tempat tidur pasien skala 1:5.

\begin{tabular}{|c|c|c|c|c|}
\hline \multicolumn{2}{|c|}{ Tegangan (Von Mises) (MPa) } & \multicolumn{2}{|c|}{ Displacement $(\mathrm{mm})$} & \multirow{2}{*}{ STEP } \\
\hline Area & Hasil & Area & Hasil & \\
\hline & 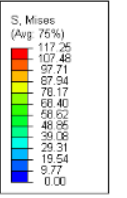 & & 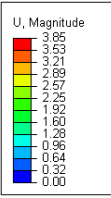 & $\begin{array}{c}1 \\
\text { Beban } 500 \mathrm{~N}\end{array}$ \\
\hline & 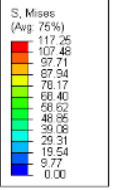 & & 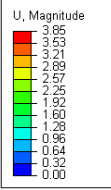 & $\begin{array}{c}2 \\
\text { Beban } 1000 \mathrm{~N}\end{array}$ \\
\hline & 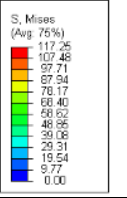 & & 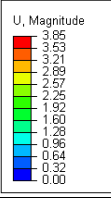 & $\begin{array}{c}3 \\
\text { Beban } 1500 \mathrm{~N}\end{array}$ \\
\hline & 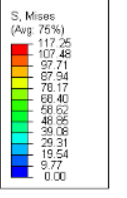 & & 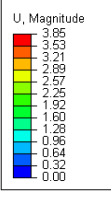 & $\begin{array}{c}4 \\
\text { Beban } 2000 \mathrm{~N}\end{array}$ \\
\hline & 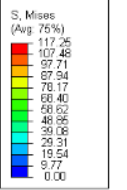 & & 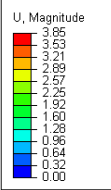 & $\begin{array}{c}5 \\
\text { Beban } 2500 \mathrm{~N}\end{array}$ \\
\hline
\end{tabular}




\begin{tabular}{|c|c|c|c|c|}
\hline \multicolumn{2}{|c|}{ Tegangan (Von Mises) (MPa) } & \multicolumn{2}{|c|}{ Displacement (mm) } & \multirow{2}{*}{ STEP } \\
\hline Area & Hasil & Area & Hasil & \\
\hline & 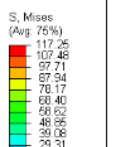 & & 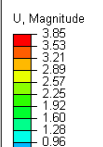 & $\begin{array}{c}6 \\
\text { Beban } 3000 \mathrm{~N}\end{array}$ \\
\hline 3 & 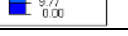 & & 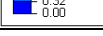 & \\
\hline
\end{tabular}

Hasil pembebanan tekan tempat tidur pasien dengan skala 1:5

\begin{tabular}{|c|c|}
\hline \multicolumn{2}{|c|}{ Simulasi Skala 1:5 } \\
\hline Beban & pergeseran \\
\hline $\mathrm{N}$ & $\mathrm{mm}$ \\
\hline 600 & 1.74 \\
\hline 500 & 1.45 \\
\hline 400 & 1.16 \\
\hline 300 & 0.87 \\
\hline 200 & 0.58 \\
\hline 100 & 0.29 \\
\hline
\end{tabular}

(a)

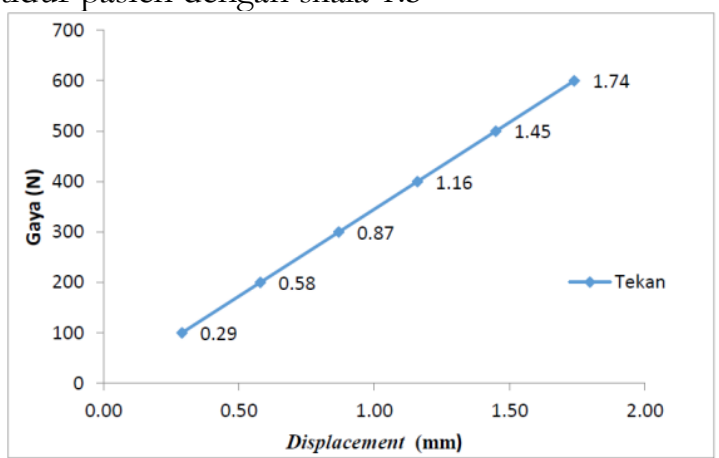

(b)

Gambar 5. (a) Hasil data simulasi, (b) Hubungan gaya dengan displacement dari hasil simulasi pengujian statis

Simulasi dengan skala 1:5 dilakukan untuk validasi perbandingan hasil antara simulasi tempat tidur pasien dengan skala 1:5 dengan eksperimen tempat tidur pasien dengan skala 1:5. Uji simulasi dilakukan dengan model static general. Pembebanan aksial maksimal sebesar $600 \mathrm{~N}$ dan pembebanan minimal 100 N. Hasil tegangan (Von Mises) dan displacement dijadikan sebagai indikator kegagalan mekanik dari model tempat tidur pasien tersebut.

\begin{tabular}{|c|c|}
\hline \multicolumn{2}{|c|}{ Eksperimen Skala 1:5 } \\
\hline Beban & pergeseran \\
\hline $\mathrm{N}$ & $\mathrm{mm}$ \\
\hline 600 & 1.68 \\
\hline 500 & 1.40 \\
\hline 400 & 1.12 \\
\hline 300 & 0.84 \\
\hline 200 & 0.56 \\
\hline 100 & 0.28 \\
\hline
\end{tabular}

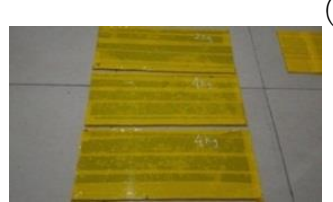

(b)

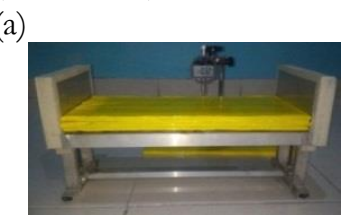

(c)

Gambar 6. (a) Hasil data pengujian, (b) Beban seberat 100 N, (c) Pengukuran menggunakan dial indikator 


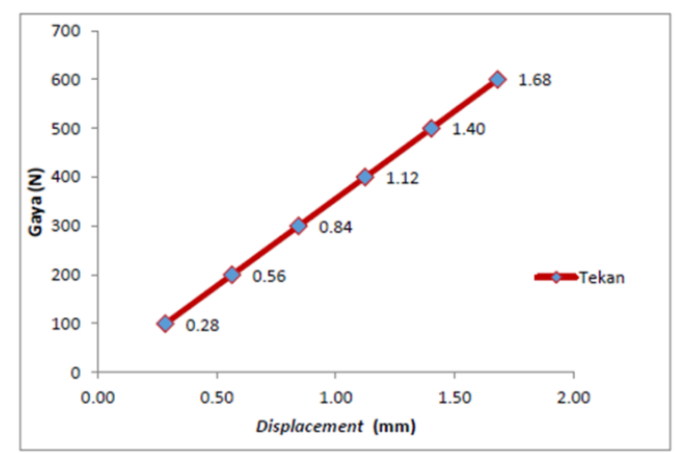

Gambar 7. Hubungan gaya dengan displacement dari hasil eksperimen pengujian statis

\section{Perbandingan antara hasil simulasi dan ekspeimen}

Perbandingan dari hasil simulasi dengan eksperimen tempat tidur pasien dengan skala 1:5 disajikan dalam bentuk grafik pada gambar 4.5 .
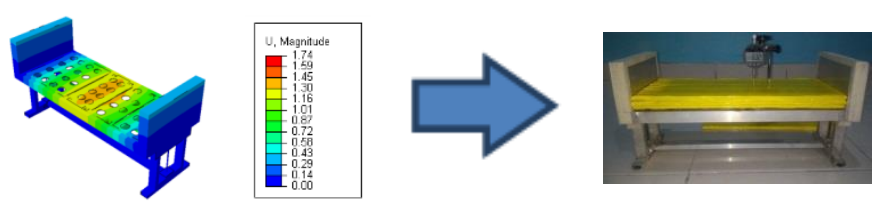

Gambar 8. Hubungan gaya dengan displacement dari hasil eksperimen pengujian statis

Grafik yang dihasilkan model simulasi dan eksperimen hasil pengujian tempat tidur pasien pada gambar 9 menunjukkan perbedaan. Perbedaan antara simulasi dan eksperimen terjadi pada nilai pergeseran atau displacement. Hasil simulasi pembebanan $600 \mathrm{~N}$ menghasilkan displacement $1.74 \mathrm{~mm}$ dalam pengujian tekan. pada eksperimen mencapai beban maksimal 600 $\mathrm{N}$, displacement yang terjadi sebesar $1.68 \mathrm{~mm}$ dalam pengujian tekan.

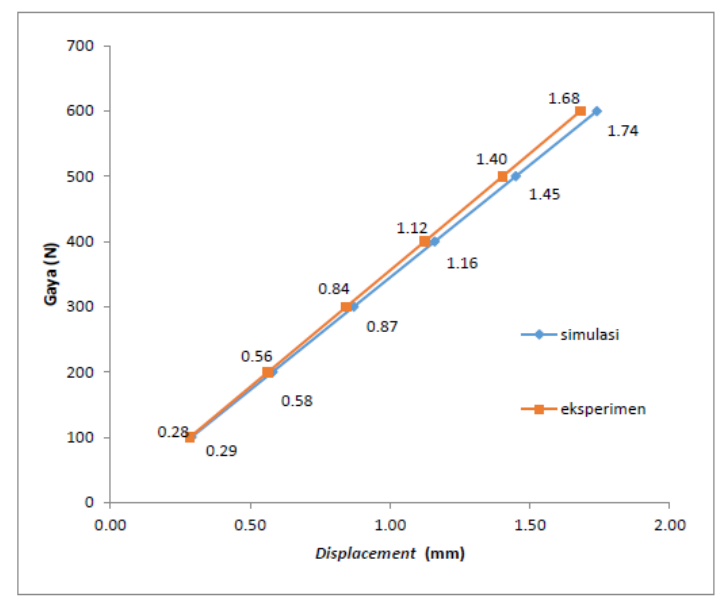

Gambar 9. Hubungan gaya dengan displacement dari hasil simulasi dan eksperimen pengujian statis. 


\section{KESIMPULAN}

Penelitian studi awal perancangan tempat tidur pasien menghasilkan berupa pengecilan ukuran tempat tidur yang sudah beredar di pasaran, analisis simulasi tempat tidur pasien skala 1:5 dengan beban $600 \mathrm{~N}$ yang menghasilkan Von Mises sebesar $67 \mathrm{MPa}$ dan displacement sebesar 1,7 mm. Untuk itu hasil tegangan (Von Mises) simulasi tempat tidur pasien nilainya lebih kecil dari yield strength aluminium 6061 T6 sebesar 275 Mpa maka bahan yang digunakan untuk tempat tidur pasien masih aman. Hasil eksperimen tempat tidur pasien skala 1:5 dengan beban $600 \mathrm{~N}$ menghasilkan displacement sebesar 1,68 mm.

\section{DAFTAR PUSTAKA}

Anonim, http://www.invacare.com/cgi-bin/imhqprd/default.jsp, diakses pada Sabtu 7 Januari 2017.

Ashby, M. M., \& Jones, D. R. H. (2012). Engineering Materials 1. Engineering Materials 1. https://doi.org/10.1016/C2009-0-64288-4

Fisher, F. (2011). ME345 Modeling and Simulation, Stevens Inst . of Technology.

L.Logan, D. (2012). A First Course in the Finite Element Method.

Pinem, M. D. (2006). Analisis Struktur Dengan Metode Elemen Hingga (Finite Element Method).

Steffen, J. R. (2014). Analysis of Machine Elements Using SolidWorks Simulation 2014. Retrieved from https://books.google.com/books?id=i7x2AwAAQBAJ\&pgis=1 